\title{
O Infiltrado: narrativas midiáticas e uma poética antropofágica ${ }^{1}$
}

\author{
Miriam Cristina Carlos Silva
}

Resumo: Com este trabalho objetiva-se discutir, a partir da comunicação e da cultura, aspectos da construção da série brasileira "O Infiltrado", especialmente no que se refere à imagem do narrador, Fred Melo Paiva, como um processo antropofágico de construção de linguagem, caracterizado pela troca cultural e pela ruptura dos cânones do gênero nas mídias. Utilizase como base o conceito de antropofagia, de Oswald de Andrade, entendido aqui como poética, ou seja, um modo de operação da linguagem. A discussão se articula, ainda, sob o olhar de pesquisadores das narrativas, entre os quais estão Walter Benjamin e Umberto Eco. Do ponto de vista empírico, a análise de alguns aspectos da série, vista como texto complexo, na concepção de luri Lotman, destaca a poética da antropofagia como possibilidade de reconfiguração dos produtos culturais e midiáticos, como um exercício de alteridade.

Palavras-chave: comunicação e cultura; antropofagia; O Infiltrado; narrativas midiáticas.

Abstract: O Infiltrado: media narratives and an anthropophagic poetics - This paper aims to discuss some construction aspects of the Brazilian TV series "O Infiltrado" from the communicative and cultural viewpoint, focusing mostly on the image of the narrator Fred Melo Paiva, as an anthropophagic process of language construction characterized by the cultural interchange and by the rupture of genre canons in media. We took as a basis the Oswald de Andrade's concept of anthropophagy, here understood as a poetics, i.e., as a way of operating the language. The discursive articulation comes from the gaze of specialists on narrative, such as Walter Benjamin and Umberto Eco. From the empirical point of view, the analysis of some aspects of the series, as a complex text according to Yuri Lotman, highlights the poetics of anthropophagy as a reconfiguration possibility for cultural and media products, as an exercise of otherness.

Keywords: communication and culture; anthropophagy; O Infiltrado; media narratives.

1 Uma primeira versão deste trabalho foi apresentada no XII Congresso Alaic 2014, no GT Comunicação Intercultural e Folkcomunicação, em Lima, Peru. O texto compõe um projeto mais amplo, sobre narrativas midiáticas, amparado pela FAPESP (2013-2015). 


\section{Introdução}

A série brasileira "O Infiltrado", em sua primeira temporada, é composta por nove episódios, exibidos pelo canal History Channel, no ano de 2013. Os temas abordados são distintos e preveem um mergulho do apresentador, Fred Melo Paiva, que, além de investigar os assuntos e apresentá-los ao público, torna-se um personagem, disposto a viver na pele uma experiência: a de se tornar pastor evangélico, segurança particular, lutador de MMA, sósia do cantor Roberto Carlos, cantor sertanejo, político e um autêntico macho man. Há também um episódio em que pretende promover a evolução social de uma cachorrinha vira-lata e, em outro, conseguir sucesso financeiro por meio da magia.

Criou-se, no site do History, para cada episódio, uma breve introdução, que oferece pistas sobre o que será abordado, com uma ilustração que, em alguns casos, complementa visualmente a mensagem:

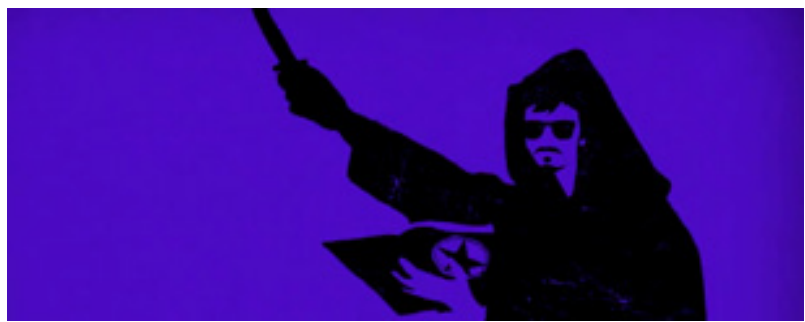

Fig.1. Episódio 09 - Magia

O Brasil tem no sincretismo religioso um de seus valores. Para se infiltrar nessa zona mista, Fred Melo Paiva, ateu, de família católica, vai experimentar estranhos rituais na tentativa louvável de ficar rico do dia para a noite².

Em todos os episódios, os resumos repetem a frase "para se infiltrar", e complementase o texto com a inserção de traços que definem a personalidade de Fred, que deverá deixar parte de suas convicções, gostos e ideais, para incorporar outros, ou seja, deve se tornar um antropófago, no sentido proposto por Oswald de Andrade, devorar e digerir o alheio, para criar algo novo. O uso do desenho, ao invés da fotografia, que já foi um contundente índice de realidade no jornalismo, é um elemento de estranhamento e de reforço da hibridização com a narrativa ficcional. A cada episódio, um dado referente a Fred é explicitado como uma convicção a ser superada para o sucesso de mergulhar na experiência, tais como a falta de fé, pois é um ateu, apesar da família católica; os ideais de não-violência, vindos de alguém que compactua com as ideias de Gandhi, combinados contraditoriamente às tendências de ativista incendiário e suas convicções punks.

2 Disponível em:<http://www.seuhistory.com/programas/o-infiltrado.html\#ad-image-0>. Acesso em: 18/10/2013. 
Como repórter e personagem, Fred postula que experimentar é viver o outro, devorá-lo. Na vertente de Walter Benjamin (1982), por privilegiar-se a experiência, matéria-prima de que se valem todos os narradores, Fred, em "O Infiltrado", aproxima-se do narrador tradicional, aquele que tem o que contar porque viveu na pele as histórias que transmitirá a seu público.

O formato dialoga com outros exemplos realizados anteriormente, em contexto mundial, desde o final da década de 90. Dovey (2008) realizou um estudo no qual defende a simulação como um modelo comum a programas como "Big Brother" (CHANELL 4, 2000), "Wife Swap" (CHANNEL 4, 2002) e "Faking It" (CHANNEL 4, 1999). A simulação, nestes casos, consiste em uma forma documental que, ao invés de se ater à observação objetiva ou reflexiva da realidade, propõe a criação de situações que não existiriam sem a presença da câmera e dos cenários. A partir das técnicas de jogo, da imitação e do fingimento, propõe-se aos participantes um conjunto dinâmico de regras que possibilitam a criação de dramas narrativos, feitos na interação entre personagens. Dovey expõe que, além de atender às tendências de mercado, à concorrência acirrada pela audiência, pelos lucros e promover o entretenimento popular, estes programas dão margem a discussões importantes sobre identidade e promovem lampejos de autenticidade, graças a uma margem na qual não se pode exercer total controle. Os programas mencionados guardam em comum com a série aqui analisada o fato de privilegiarem o entretenimento, mas também a ruptura com os cânones do gênero documental, a simulação de situações e, portanto, a incorporação de aspectos dramatúrgicos, além da capacidade de se abrirem sobre o debate das questões de identidade, preconceitos, cultura e alteridade. O que distingue "O Infiltrado" é a condução narrativa hiperbolicamente crítica e bem-humorada de Fred Melo Paiva, narrador e protagonista da série, estruturada, sobretudo por essa utilização do humor em várias de suas nuances, em uma poética antropofágica.

Ao ser classificada como série, "O Infiltrado" propõe um contrato com o telespectador, visto como leitor-modelo, adaptando-se o conceito proposto por Umberto Eco (1993), de um interlocutor ideal, previsto com suas singularidades para a fruição da obra. O leitormodelo, o público, em um primeiro momento, espera que o programa atenda a normas estabelecidas convencionalmente pela linguagem das mídias. Entretanto, no objeto em questão, não se seguem os padrões ditados pela linguagem das séries documentais. O que se concretiza é uma poética antropofágica, um modo de operar a linguagem audiovisual marcado pela aproximação de elementos aparentemente distantes.

A antropofagia de Oswald de Andrade, conceito-chave utilizado neste trabalho, parte de uma metáfora para chegar a uma teoria da cultura brasileira. Definida como um processo de devoração, a poética antropofágica destaca a transformação dos produtos da cultura, mediante a incorporação do alheio, da diferença, em um processo de deglutição crítica, em que a junção de duas ou mais formas de culturas distintas (ou de seus produtos) darão origem a uma terceira. Os indícios de uma teoria da cultura brasileira, proposta 
por Oswald de Andrade, aparecem pela primeira vez no Manifesto Antropófago (1928), e permeiam a obra mais inventiva do poeta, ensaísta, crítico, romancista, dramaturgo e jornalista. Entre os elementos apontados como marcas antropofágicas, destaca-se a utilização de um humor crítico, que prevê a incorporação do alheio e a sua digestão, para a transformação em um novo produto, amalgamado. A citação, a paráfrase, a paródia, a colagem e a montagem são as principais formas utilizadas:

Da incorporação dos materiais já existentes na cultura, metáfora da devoração, expressa pelo Manifesto Antropófago, o processo erótico de comunhão em que a apropriação do alheio serve para gerar um produto híbrido e novo, renovado porque fora de seu contexto, com um potencial lúdico mais visível - e a paródia, jogo por excelência, amplia seu poder comunicativo por trazer elementos da tradição e / ou do alheio que, embora reconhecíveis, já não são mais aquilo que Ihes deu origem (SILVA, 2007, p. 22).

Em "O Infiltrado" o amálgama se faz visível a começar pelos temas abordados, distintos, incomuns nas mídias convencionais. São temas que conduzirão a narrativas inesperadas, com desfechos surpreendentes, graças à exploração, pelo narrador, dos aspectos humanos, poéticos e humorísticos de cada situação.

A partir de alguns recortes sobre os processos de linguagem e sobre a imagem do narrador, utilizados em "O Infiltrado", conclui-se que a série resulta em uma narrativa midiática hibridizada, transformada por um conjunto de rupturas e amálgamas que podem possibilitar a crítica e a reflexão sobre a alteridade.

\section{Narrativas midiáticas: uma poética antropofágica}

É possível considerar a série "O Infiltrado" como um texto da cultura, de acordo com a concepção de Lotman (1978), que entende a cultura como um grande texto, composto de outros textos; um sistema que, em um processo tradutório, reconfigura-se continuamente. Também é esta a máxima da antropofagia: traduzir, trocar culturas, sabendo-se que todo processo de tradução consiste em recriação, ou seja, reconfiguração. Como texto da cultura, "O Infiltrado" configura-se a partir de um código híbrido, composto por imagem, som e palavra, que, combinados, resultam em uma narrativa cuja finalidade é traduzir mensagens. Embora se coloque como série e explicite características do jornalismo, como texto cultural e documental que é, propõe uma abertura dinâmica que, ao reestruturar a linguagem jornalística do documentário, remodela também o olhar do público, tanto para a linguagem quanto para o que ela representa: o mundo, o eu e o outro. Além disto, o conceito de gênero é rompido e transformado em uma mescla.

Não se trata, desta forma, de uma narrativa fechada. Construída a partir da complexidade, preserva e explicita características da reportagem convencional, 
pois envolve a presença de um jornalista, possui caráter investigativo, faz uso da entrevista com diversas fontes, mas também aproxima-se do ficcional, já que faz do narrador o personagem de uma trama. Ao dialogar com o entretenimento, utiliza-se do inusitado, do inesperado e especialmente do humor, presente em todos os episódios.

Oswald de Andrade (1990), em seu Manifesto Antropófago (1928), ressaltou a alegria como prova dos nove, utilizando o humor como fundamento para a sua poética. Ao lançar mão de recursos como a paródia, a paráfrase, a caricatura e o trocadilho, possibilitou um pensamento crítico e autocrítico, do qual não escapam as instituições sociais, a natureza humana, a sociedade burguesa e a linguagem artística. Defendeu a "contribuição milionária de todos os erros" (1990, p. 66). Nessa perspectiva de assimilar o que poderia ser considerado um erro, Fred Melo Paiva ${ }^{3}$, jornalista, é o apresentador e personagem principal em "O Infiltrado" e, vindo do jornalismo impresso, sua inexperiência com a linguagem audiovisual poderia ser considerada um desacerto: ficar de costas em cena, não olhar para a câmera, improvisar, interromper o entrevistado com uma piada ou, ao contrário, deixar-se interromper pelos interlocutores, além de receber respostas marcadas pela irritação ou indiferença do interlocutor, foram marcas incorporadas como traços de identidade, o que resultou em um modelo não hegemônico de repórter e de reportagem.

Fred Melo Paiva, para além de um jornalista supostamente imparcial, conjuga uma abordagem que esbarra no autobiográfico, confessional. Importa o fato, mas, sobretudo, o desenrolar da narrativa, a sequência de fatos experimentados por Fred. A subjetividade, a parcialidade, o juízo de valor, a postura ideológica, ao invés de nublados, são ressaltados. O início de cada um dos episódios conta com uma apresentação do narrador/personagem, realizada em primeira pessoa, com o uso do nome próprio, abreviado (Fred, ao invés de Frederico), sem o sobrenome, reforçando a intimidade com o público:

Eu sou o Fred. Minha profissão de jornalista me leva a situações inusitadas e pessoas diferentes. Mas eu já fui punk. E um ex-punk não abre mão de seu jeito de pensar. Eu poderia ser um repórter convencional. Mas eu decidi experimentar um outro ponto de vista. Nessa série eu sou "O Infiltrado"4.

Dovey (2008) explica que certos elementos do factual contemporâneo, especialmente a ênfase na primeira pessoa e a intimidade na mídia, devem ser atribuídos não apenas a uma maior mercantilização da TV, mas também como tentativa de representar a identidade e sociabilidade.

A imagem do narrador documental, ao se mesclar a outras formas de atuação narrativa e a outros modelos aparentemente inconciliáveis (um jornalista de TV e um punk, que não abre mão de sua forma de pensar), reconfigura a relação do jornalismo com o público e do público com a significação dos fatos narrados. Esta poética antropofágica

3 Os depoimentos de Fred Melo Paiva e Krishna Mahon sobre "O Infiltrado" estão disponíveis em: <http://netlabtv. com.br/o-infiltrado/> Acesso em 21/10/13.

4 Disponível em: <http://www.youtube.com/watch?v=gzRmrsi9UMc $>$. Acesso em 21/10/2013. 
passa pelo reconhecimento de traços de gêneros distintos, canonizados e segmentados e que, somados, tornam a narrativa mais complexa, pela permissão de se construir em um lugar inespecífico, aberto, um "entre". O que se pretende é oferecer um "outro ponto de vista", mas não o único. Para Janotti Júnior:

(...) os gêneros delimitam as produções de sentido, demarcando a significação e os aspectos ideológicos dos textos, bem como o alcance comercial (e o público-alvo) dos produtos midiáticos. Toda definição de gênero pressupõe uma demarcação negativa e / ou comparativa com outros gêneros, ou seja, analisar um produto midiático através dessa perspectiva pressupõe perceber as relações entre esse produto e outros de diferentes gêneros, compará-lo com expressões canônicas ou similares dentro do mesmo paradigma. Os gêneros são dinâmicos justamente porque respondem a determinadas condições de produção e reconhecimento, indicativos das possibilidades de produção de sentido e de interação entre os modos de produção / circulação / consumo de produtos midiáticos (2006, p. 59).

Uma possível aproximação com este contrato entre produtores e público, proporcionado pelo gênero midiático, está na definição de Umberto Eco a respeito de dois tipos de leitores, o de primeiro nível, "que quer saber muito bem como a história termina" (1994, p. 33), e o de segundo nível, "que se pergunta que tipo de leitor a história deseja que ele se torne e que quer descobrir precisamente como o autor-modelo faz para guiar o leitor" (idem). Acrescenta-se às explanações de Eco o entendimento de um leitor-modelo de primeiro nível como aquele disposto a obedecer o contrato, a atender ao que é proposto, seguindo as regras do jogo sem maiores sustos: o leitor já prevê os conteúdos e domina as formas que necessitará traduzir, sem um grande esforço. Já o leitor de segundo nível quer ir além e se dispõe a enfrentar um processo de metalinguagem, enredando-se pelo texto e suas amarrações, a fim de desvendá-lo como estratégia comunicacional e de encontrar os mecanismos que remetem às fórmulas conhecidas e aqueles que levam à ruptura e ao novo.

"O Infiltrado" possibilita que o leitor-modelo desejado ultrapasse o grande público do jornalismo convencional, aspirando a um público que se permita a leitura de referentes mais complexos, e que busque ser provocado a refletir, não apenas mediante conteúdos distintos daqueles ofertados pela grande mídia, mas também de formatos inovadores, cuja linguagem supere os padrões desgastados pela repetição. É provável que "O Infiltrado" tenha sido pensado para um leitor de segundo nível, mas poderá atender também a um leitor-modelo de primeiro nível, que não deseje ultrapassar as camadas de entretenimento que compõem os episódios, camadas estas que, para um leitor de segundo nível, levarão à reflexão crítica, ou seja, pode-se apenas rir ou, pode este riso ser acompanhado de uma melancólica reflexão.

O que ocorre, então, é a proposição de um formato calcado em instruções de produção, mas também de leitura. É possível, portanto, falar-se em gênero midiático, 
levando-se em conta a materialidade dos meios de comunicação e sua inserção social, pois só há produção de sentido na interação entre sujeitos produtores e receptores. Janotti Junior propõe que

a configuração de determinados traços estilísticos do gênero em um produto midiático define um processo de produção de sentido e, consequentemente, de comunicação que pressupõe regras formais e ritualizações partilhadas por produtores e audiência (2006, p. 60).

Na série "O Infiltrado", o que se oferece ao leitor-modelo é uma proposta de leitura e interpretação complexa que passa pelo estranhamento do paradigma da reportagem convencional. Ao invés de apenas situar, desloca-se a audiência em relação ao gênero proposto. A antropofagia, neste caso, consiste em conhecer, estranhar (ou desconhecer) e realinhar (digerir e transformar) as expectativas a um outro modelo, que funciona como uma ironia em relação ao cânone. Esse estranhamento, que não invalida o reconhecimento do modelo da reportagem televisiva, reforça a afirmação de que "os gêneros são, antes de tudo, modelos (paradigmas) dinâmicos e não fórmulas ossificadas" (JANOTTI JÚNIOR, 2006, p. 59). Começa-se pela imagem do narrador/jornalista. Magro, usando roupas casuais, barba por fazer, cabelos desalinhados, sotaque mineiro, mochila nas costas e deslocando-se na trama por meio de uma bicicleta dobrável, Fred se contrapõe ao repórter de aparência impecável, terno e gravata, microfone na mão, nome e sobrenome.

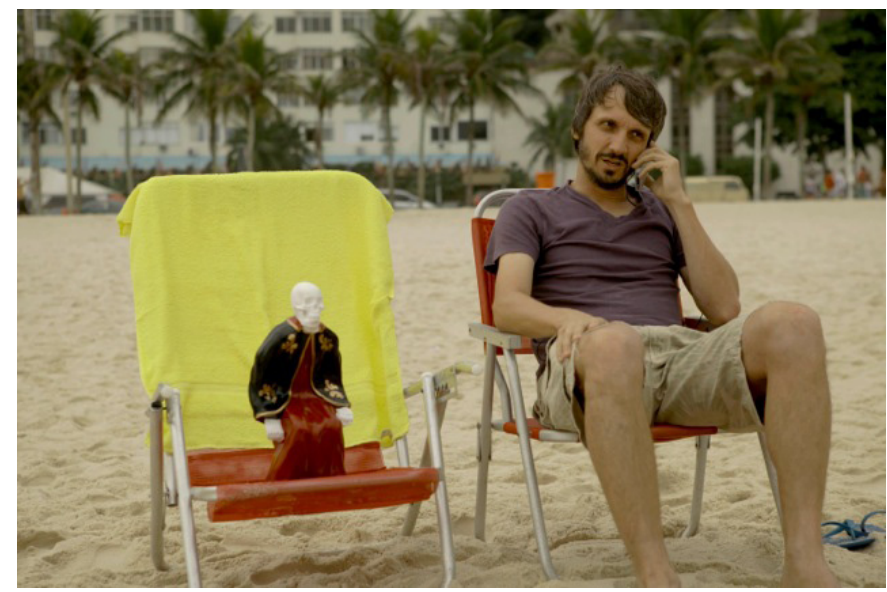

Fig.2.Fred Melo Paiva em cena do episódio "Magia", disponível em:

<http://latam.aetn.com/THC/br/o-infiltrado/mobile/images/galeria/the-history-channel-o-infiltrado-magia-01.jpg > . Acesso em: 24 fev. 2013

Segundo Gideon Boulting 5 , diretor da série, são respeitadas algumas regras básicas para que seja mantida a naturalidade do programa: a primeira é que Fred não pode ter

5 Disponível em: <http://netlabtv.com.br/o-infiltrado/>. Acesso em: 28 set. 2013. 
nenhum contato prévio com os personagens. Entende-se este processo como a criação de um dispositivo, não como a reprodução de uma matriz que estrutura uma materialidade e estabelece uma expectativa a ser cumprida na relação texto e leitor, mas como uma possibilidade de estranhamento, um exercício de descontextualização, muito utilizado na poética de Oswald de Andrade. A segunda regra prevê que o apresentador não deve mentir para si mesmo, tampouco fazer alguma coisa que realmente não deseje. Percebe-se que este processo é difícil de ser assegurado, já que, como personagem que é, o jornalista pode passar a interpretar ao invés de apenas viver a experiência. E a terceira regra: caso Fred sinta desejo de brincar ou criticar o personagem, deve fazer isto em cena, concedendo direito de resposta, neste sentido, na maior parte do tempo as reações são inesperadas e neste caso, entende-se que se dá o acontecimento, que pressupõe:

um desdobramento dos corpos e das subjetividades em possibilidades que ultrapassam suas próprias medidas; ultrapassam qualquer medida previamente pensável. A ideia fundamental da utilização do dispositivo está na possibilidade da arte de enxergar o mundo a partir de uma desprogramação (MIGLIORIN, 2006, p. 88).

De acordo com Migliorin, na esteira de Deleuze em Logique du sens (1969), "o acontecimento não é decifrável, não aponta para o que não está ali, não se remete a relações que incluam corpos ausentes do encontro que os produziu" (2006, p.88). Entende-se este acontecimento como um processo de deslocamento, de alteridade, no qual é possível enxergar melhor a si mesmo e ao outro. A produção do acontecimento parece aproximar-se do conceito de simulação proposto por Dovey (2008): a simulação é usada para representar processos complexos, com múltiplos agentes e causalidades, e parece responder a uma necessidade teórica para formas de produção de conhecimento que têm em conta os níveis de interação entre os agentes de nível micro e forças de nível macro, bem como para atender a uma necessidade articulada por teóricos pós-modernos de um método de representação que tem em conta as mudanças rápidas.

Um exemplo de acontecimento pode ser extraído do episódio sobre "Sósias", no qual Fred tentará se tornar um cover de Roberto Carlos. Logo na abertura o narrador afirma que "o cinema e a TV inventaram a celebridade, essa praga do mundo moderno". É evidente o componente crítico e reflexivo da fala, que segue utilizando uma paráfrase da máxima "penso, logo existo", com "sou visto, logo existo. Esse é o mantra do homo videns desde o século XX".

Já em sua introdução, o episódio fornece uma possibilidade de se pensar a condição humana em relação aos meios de comunicação, a produção de celebridades, a busca da fama a qualquer preço: tudo isto discutido pelo viés do humor. Fred Melo Paiva, que além de apresentador é autor dos textos, literalmente o narrador de "O Infiltrado", assim como Oswald de Andrade, destrói a superfície das coisas, convidando o público a virá-las pelo avesso. Chamie explica que: 
a moral oswaldiana, portanto, é a moral do avesso, ou seja, da irreverência, da ironia, e da piada, armas de ataque contra a seriedade e seus modelos. Oswald parece ter entendido que a atitude séria está sempre do lado direito, e o lado direito, muitas vezes, é um mero fenômeno fruto de um consentimento sem razão (CHAMIE, 1976, p. 5).

A postura irônica de Fred Melo Paiva como apresentador leva a esse avesso. Não há distinção entre cultura alta e baixa, pois qualquer assunto pode ser abordado, ou seja, desestabilizam-se os tabus - e é sabido que Oswald de Andrade propunha desmontar as noções de uma cultura letrada, erudita, utilizando-se da linguagem popular, além de apregoar a transformação do tabu em totem. E também não há lado direito ou esquerdo, pois estes são apenas um ponto de vista. No episódio sobre MMA, Fred, que é contra a violência, frequenta uma academia precária e conhece a batalha pela sobrevivência de homens simples que sonham ser campeões. Com eles, aprende sobre amizade, lealdade, persistência e resignação e conclui que torcerá para sempre por essas pessoas que conheceu.

Há o uso da ironia, quando Fred expõe, no episódio "Sósias": "Para me infiltrar nesse universo dos paralelos, lancei mão da minha incrível semelhança com Roberto Carlos. Mesmo correndo o risco de virar o bobo da corte" ${ }^{\prime 6}$. A semelhança entre Roberto Carlos e Fred é inexistente, e todas as tentativas do narrador, agora personagem, de se parecer mais com o "Rei" são fracassadas. Porém a condição de sósia de Fred revela-se menos absurda que a de seus entrevistados, sósias de fato.

Em um bar, acompanhado de um sósia de Pelé, Fred vê pessoas abordarem a cópia, pedirem fotos e comentarem que o "Pelé é único, não existe outro igual". Na narrativa em off, Fred dispara: "Cê que pensa...". Ainda no episódio sobre os sósias, a produção aparentemente surpreende Fred Melo Paiva ao inserir um sósia do próprio repórter, que aparece de mochila nas costas, camiseta e bicicleta iguais às do narrador. Isto ocorre quando o repórter percebe que não conseguirá chegar ao seu intento, tornar-se um cover de Roberto Carlos, e em conversa com a empresária de Carlos Evaney, sósia oficial de Roberto Carlos, tem a ideia de ser tornar uma cópia da cópia, ou seja, se não é possível ser sósia do original, tentará ser cover do sósia. Trata-se de um ponto alto de humor na trama, mas também de um momento que permite a reflexão: quem, afinal, é cópia de quem? Quem somos nós? O que é ser original e o quanto se é autêntico? Assim, cópias de Pelé, Chacrinha, Roberto Carlos, Cher, Neymar, Rita Lee, Raul Seixas, entre outros, são o pano de fundo para uma discussão que abarca o universo das celebridades, o real e o falso e o que move alguém na tentativa de se tornar outro. Nos últimos momentos do episódio, Fred, na Urca, em frente à casa de Roberto Carlos, sai a passeio de barco, acompanhado por Evaney, que grita apavorado com o movimento das ondas. Alguns minutos depois, Evaney aparece em primeiro plano, dirigindo-se à câmera e convidando a todos os espectadores que façam com ele esse passeio. Fred interpela: "Depois de você

6 Disponível em: <http://www.youtube.com/watch?v=gzRmrsi9UMc>. Acesso em: 21 out. 2013. 
fazer essa patacoada toda aqui nesse barco, você chama todo mundo pra viajar com você??" E Evaney responde: "Pois é, bicho". E os dois riem com espontaneidade. Evaney com uma espontaneidade até então reprimida. E este momento do riso, além daquele dos gritos no barco, parecem ser os pontos em que Evaney se torna mais ele mesmo e menos cover de Roberto Carlos. Ocorre, assim, um desdobramento de subjetividades a partir do diálogo entre entrevistador e entrevistado, ambos personagens, pelo uso do inesperado e do humor como estratégia narrativa, o que se pode classificar como produção de acontecimentos. É possível uma aproximação com o conceito de dispositivo, definido como "estratégia narrativa capaz de produzir um acontecimento na imagem e no mundo" (MIGLIORIN, 2006, p. 82):

O artista / diretor constrói algo que dispara um movimento não presente no mundo, isto é, um dispositivo. É esse novo movimento que irá produzir um acontecimento não dominado pelo artista. Sua produção, nesse sentido, transita entre um extremo domínio - do dispositivo - e uma larga falta de controle dos efeitos e eventuais acontecimentos. O dispositivo é a introdução de linhas ativadoras em um universo escolhido (MIGLIORIN, 2006, p. 83).

Migliorin define o dispositivo como "uma ativação do real" (2006, p. 84). É pertinente lembrar que um dos gêneros midiáticos com os quais "O Infiltrado" dialoga é o reality show. Esse diálogo investe na produção de um documental no qual o foco são os personagens e suas reações, na interação com o repórter, ele também um personagem sobre o qual não se tem controle absoluto. Não se privilegia o fato prévio, a ser mediado e transformado em acontecimento midiático.

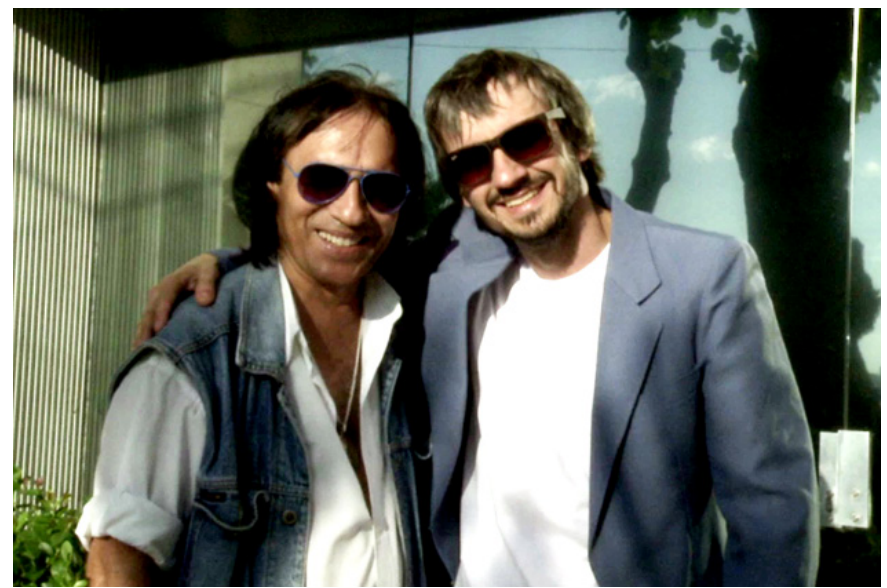

Fig.3. Carlos Evaney, sósia de Roberto Carlos e Fred, em cena do episódio "O infiltrado no mundo dos sósias. Disponível em: <http://latam.aetn.com/THC/br/o-infiltrado/mobile/images/galeria/the-history-channel-o-infiltradososias-00022.png> Acesso em: 21 set. 2013.

7 Disponível em: <http://www.youtube.com/watch?v=gzRmrsi9UMc> . Acesso em: 21 out. 2013. 
Ao evidenciar que não se parece com Roberto Carlos e que tampouco se parece com um repórter convencional, Fred enfatiza ser igual a um qualquer, o que o aproxima do público. Um repórter televisivo costuma atender a estratégias de construção de imagem oferecidas como normas, um padrão a ser obedecido, a fim de que se possa interagir com o público, no sentido de se respeitar determinadas especificidades midiáticas inscritas no gênero reportagem. O corpo, portanto, transformado agora em imagem, é um elemento fundamental na construção do repórter. É um texto da cultura (LOTMAN, 1978), que será lido e interpretado. O corpo do repórter materializa em sua gestualidade aquilo que a audiência espera: deve ser neutro, formal, ereto e discreto; um corpo padronizado e institucionalizado. Mas Fred incorpora uma outra forma de se relacionar com aquilo que narra, indo, com seu próprio corpo, carregado de textos a serem lidos, de encontro ao que se espera.

Ao contrário de "O Infiltrado", as narrativas jornalísticas, em geral, tendem a apagar o narrador. Toma-se como base Resende, que expõe o fato de que se trata de narrativas autoritárias, "exatamente porque propõem o apagamento daquele que fala" (RESENDE, 2006, p. 164):

O jornalista, diante de pressupostos conceituais que formatam o seu texto a necessária busca da verdade, valor encravado na pressuposta imparcialidade de quem relata o fato - se esvai do narrado e raramente se apresenta enquanto autor. Não há, na perspectiva da narrativa jornalística tradicional, alguém que conta a história (ibid, 2006, p. 164).

Percebe-se um jogo constante entre o comum da pessoa Fred, incomum para um repórter de TV. No episódio "Magia", Fred conversa com a esposa, pelo celular, sobre o fato de sua conta bancária ainda não demonstrar sinais de evolução, apesar de todos os rituais de magia dos quais participou para enriquecer. Nesse mesmo episódio ele menciona o fato de que se conseguisse chegar ao salário de William Bonner, isto já seria um resultado mágico. Percebe-se no uso da piada também a presença da metalinguagem e do questionamento relacionado ao valor dos produtos midiáticos.

É nesta combinação antropofágica de corpos que a imagem do narrador se particulariza e proclama a impossibilidade de se distinguir por completo a pessoa comum do narrador/ personagem. A narrativa em off, em primeira pessoa, marcada pela voz particular, com sotaque mineiro (comum e incomum) e o corpo (particular e comum) de Fred, o fanático torcedor do Galo, morador do Rio de Janeiro, funciona como uma interferência direta do narrador que, além de avaliar os personagens com os quais contracena e as situações experimentadas, visa emitir um juízo, uma moral da história, uma observação sobre a natureza das coisas, e pode ser tomada também como um conselho, um reforço de suas próprias convicções ou a constatação de um aprendizado, lembrando-se aqui o narrador de Benjamin (1982), ou seja, aquele que sabe dar conselhos para todas as situações, 
bem como aquele capaz de narrar porque viveu a experiência com o próprio corpo. $\mathrm{Ou}$, ainda, aquele que, de forma antropofágica, devorou o outro, deixou-se devorar pelo outro, produziu um acontecimento comunicacional, ou seja, a "criação de um ambiente comum em que os dois lados participam e extraem de sua participação algo novo, inesperado, que não estava em nenhum deles, e que altera o estatuto anterior de ambos, apesar de as diferenças individuais se manterem" (MARCONDES FILHO, 2004, p.15).

\section{Considerações finais}

As narrativas midiáticas são possibilidades de tradução da experiência, pois permitem criar e recriar o mundo, não apenas pelos enredos que comportam, mas pela linguagem que as materializa.

A tradução, na esteira de Lotman (1978), além de uma troca de linguagens é, fundamentalmente, uma troca de culturas. A partir desta afirmação, concluímos que a imagem do narrador em "O Infiltrado" traduz uma parcialidade controversa, por isso mesmo crítica. Há uma tomada de posição, da qual não se exclui a assunção dos preconceitos do narrador, no caso, jornalista, que se coloca, antropofagicamente, como personagem, experimentando, o que possibilita mudar ou reforçar suas convicções, ou seja, trocar e traduzir, linguagens e culturas.

Ao escancarar a condição humana, plural, provisória e movediça, "O Infiltrado" destaca a condição humana e provisória do jornalismo, questionando, nas rupturas da linguagem jornalística tradicional, canonizada, sua busca supostamente imparcial pela verdade.

A presença do humor como tônica e da função emotiva, que destaca o emissor, caracterizam a contundência crítica de uma prática que permanece jornalística, mas fortemente opinativa e colaborativa, em uma vertente não-institucional, também por isso antropofágica.

No episódio "Sósias", ao entrevistar Paulete, transexual que realizou dezenas de cirurgias para se tornar sósia de Cher, Fred diz à personagem que não é necessário que ela se dirija o tempo todo para a câmera. Ao pedir que ela fale com naturalidade, ouve de Paulete que ela conhece todas as suas angulações e que, de frente, ela fica mais Cher. A narrativa, portanto, constrói-se coletivamente, no embate de ideias entre atores, produtores e público, nas experiências capazes de transformar cada um dos participantes que provocam e se deixam provocar, mas também a partir dos mecanismos que estruturam a linguagem, neste caso, metalinguagem, pois se chama a atenção do público para o fato de que se está diante de uma narrativa midiática, não de uma verdade estabelecida.

A proposta do narrador construído em "O Infiltrado" está em não querer estabelecer um jornalismo-verdade, mas um jornalismo em que a verdade surge ao mesmo tempo de modo íntimo e coletivo, a partir do sujeito que narra e de sua interpretação dos fatos, mas também da ação transformadora dos personagens com os quais atua, na confluência de intersubjetividades. 
Fred é a voz subjetiva que relata a experiência, intersubjetiva, com todas as suas contradições. A diferença está no fato de que a imagem deste repórter-narrador inclui as subjetividades de forma explícita, com os valores, gestos e preconceitos do narradorpersonagem e seus interlocutores. Por sua explícita parcialidade e comicidade, constitui-se como uma linguagem criativa, poética e inovadora, portadora de pontos de vista abertos ao questionamento e à crítica.

Miriam Cristina Carlos Silva é professora do Mestrado em Comunicação e Cultura da Universidade de Sorocaba. É doutora em Comunicação e Semiótica pela PUCSP e pósdoutora em Comunicação Social pela PUCRS.

\section{Referências}

ANDRADE, O. A utopia antropofágica. São Paulo: Globo, 1990.

BENJAMIN, W. O narrador: Considerações sobre a obra de Nikolai Leskov. In: Magia, técnica, arte, política. São Paulo: Brasiliense, 1982.

CHAMIE, M. A linguagem virtual. São Paulo: Quiron, 1976.

DELEUZE, G. Logique du sens. Paris: Les Editions de Minuite, 1969.

DOVEY, J. Simulating the public sphere. In: AUSTIN, T. and JONG, W.. Rethinking Documentary: New Perspectives and Practices. New York: McGraw Hill, 2008.

ECO, U. Interpretação e superinterpretação. São Paulo: Martins Fontes, 1993.

Seis passeios pelos bosques da ficção. São Paulo: Companhia das Letras, 1994.

JANOTTI JUNIOR, J. S. Dos gêneros textuais, dos discursos e das canções: uma proposta de análise da música popular massiva a partir da noção de gênero midiático. In: LEMOS, Andre et al. Narrativas midiáticas contemporâneas. Porto Alegre: Sulina, 2006.

LOTMAN, I. A estrutura do texto artístico. Lisboa: Estampa, 1978.

MARCONDES FILHO, C. Até que ponto, de fato, nos comunicamos? Uma reflexão sobre o processo de individuação e formação. São Paulo: Paulus, 2004.

MIGLIORIN, C. O dispositivo como estratégia narrativa. In: LEMOS, Andre et al. Narrativas midiáticas contemporâneas. Porto Alegre: Sulina,2006.

RESENDE, F. O jornalismo e a enunciação: perspectivas para um narrador-jornalista. In: LEMOS, Andre et al. Narrativas midiáticas contemporâneas. Porto Alegre: Sulina, 2006.

SILVA, M. C. C. Comunicação e cultura antropofágicas: mídia, corpo e paisagem na erótico-poética oswaldiana. Porto Alegre: Sulina, 2007. 